\title{
Genome characteristics of facultatively symbiotic Frankia sp. strains reflect host range and host plant biogeography
}

Philippe Normand, ${ }^{1}$ Pascal Lapierre, ${ }^{2}$ Louis S. Tisa, ${ }^{3}$ Johann Peter Gogarten, ${ }^{2}$ Nicole Alloisio, ${ }^{1}$ Emilie Bagnarol, ${ }^{1}$ Carla A. Bassi,, ${ }^{2}$ Alison M. Berry, ${ }^{4}$ Derek M. Bickhart, ${ }^{2}$ Nathalie Choisne, ${ }^{5,6}$ Arnaud Couloux, ${ }^{6}$ Benoit Cournoyer, ${ }^{1}$ Stephane Cruveiller, ${ }^{7}$ Vincent Daubin, ${ }^{8}$ Nadia Demange, ${ }^{6}$ Maria Pilar Francino, ${ }^{9}$ Eugene Goltsman, ${ }^{9}$ Ying Huang, ${ }^{2}$ Olga R. Kopp, ${ }^{10}$ Laurent Labarre, ${ }^{7}$ Alla Lapidus, ${ }^{9}$ Celine Lavire, ${ }^{1}$ Joelle Marechal, ${ }^{1}$ Michele Martinez, ${ }^{9}$ Juliana E. Mastronunzio, ${ }^{2}$ Beth C. Mullin, ${ }^{10}$ James Niemann, ${ }^{3}$ Pierre Pujic, ${ }^{1}$ Tania Rawnsley, ${ }^{3}$ Zoe Rouy, ${ }^{7}$ Chantal Schenowitz, ${ }^{6}$ Anita Sellstedt, ${ }^{11}$ Fernando Tavares, ${ }^{12}$ Jeffrey P. Tomkins, ${ }^{13}$ David Vallenet, $^{7}$ Claudio Valverde, ${ }^{14}$ Luis G. Wall, ${ }^{14}$ Ying Wang, ${ }^{10}$ Claudine Medigue, $^{7}$ and David R. Benson ${ }^{2,15}$

\begin{abstract}
${ }^{1}$ Université de Lyon, Unité Mixte de Recherche, Centre National de la Recherche Scientifique (UMR CNRS), 5557 Ecologie Microbienne, IFR41 Bio Environnement et Santé, Université Lyon I, Villeurbanne 69622 cedex, France; ${ }^{2}$ Department of Molecular and Cell Biology, University of Connecticut, Storrs, Connecticut 06279, USA; ${ }^{3}$ Department of Microbiology, University of New Hampshire, Durham, New Hampshire, 03824, USA; ${ }^{4}$ Department of Plant Sciences, University of California, Davis, California 95616, USA; ${ }^{5}$ I'Institut National de la Recherche Agronomique-Unité de Recherche en Génomique Végétale (INRA-URGV), 91057 Evry cedex, France; ${ }^{6}$ Genoscope, Centre National de Séquençage, 91057 Evry cedex, France; ${ }^{7}$ Genoscope, CNRS-UMR 8030, Atelier de Génomique Comparative, 91006 Evry cedex, France; ${ }^{8}$ Bioinformatics and Evolutionary Genomics Laboratory, UMR CNRS 5558, Université Lyon I, Villeurbanne 69622 cedex, France; ${ }^{9}$ DOE Joint Genome Institute, Walnut Creek, California 94598 , USA; ${ }^{10}$ Department of Biochemistry \& Cellular \& Molecular Biology and The Genome Science \& Technology Program, The University of Tennessee, Knoxville, Tennessee 37996, USA; ${ }^{11}$ Department of Plant Physiology, Umeå University, S-90187 Umeå, Sweden; ${ }^{12}$ Instituto de Biologia Molecular e Celular, Universidade do Porto, 4150-180 Porto, Portugal; ${ }^{13}$ Clemson University Genomics Institute, Clemson, South Carolina 29634, USA; ${ }^{4}$ Programa Interacciones Biológicas, Departamento de Ciencia y Tecnología, Universidad Nacional de Quilmes, Bernal B1876BXD, Argentina
\end{abstract}

Soil bacteria that also form mutualistic symbioses in plants encounter two major levels of selection. One occurs during adaptation to and survival in soil, and the other occurs in concert with host plant speciation and adaptation. Actinobacteria from the genus Frankia are facultative symbionts that form $\mathbf{N}_{2}$-fixing root nodules on diverse and globally distributed angiosperms in the "actinorhizal" symbioses. Three closely related clades of Frankia sp. strains are recognized; members of each clade infect a subset of plants from among eight angiosperm families. We sequenced the genomes from three strains; their sizes varied from $5.43 \mathrm{Mbp}$ for a narrow host range strain (Frankia sp. strain HFPCcl3) to $7.50 \mathrm{Mbp}$ for a medium host range strain (Frankia alni strain ACN14a) to $9.04 \mathrm{Mbp}$ for a broad host range strain (Frankia sp. strain EAN1pec.) This size divergence is the largest yet reported for such closely related soil bacteria (97.8\%-98.9\% identity of $16 \mathrm{~S}$ rRNA genes). The extent of gene deletion, duplication, and acquisition is in concert with the biogeographic history of the symbioses and host plant speciation. Host plant isolation favored genome contraction, whereas host plant diversification favored genome expansion. The results support the idea that major genome expansions as well as reductions can occur in facultative symbiotic soil bacteria as they respond to new environments in the context of their symbioses.

[The genome sequences for Frankia strains Ccl3, ACN14a, and EAN1pec have been submitted to GenBank under accession nos. CPO00249, CT573213, and AAII00000000, respectively.]

\footnotetext{
${ }^{15}$ Corresponding author.

E-mail david.benson@uconn.edu; fax 860-486-4331.

Article published online before print. Article and publication date are at http:// www.genome.org/cgi/doi/10.1101/gr.5798407.
}

Two very different groups of bacteria can form nitrogen-fixing root nodules on angiosperms: Gram-negative proteobacteria from several families, and high Mol\% G+C Gram-positive actinobacteria in the family Frankiaceae. Nodulating proteobacteria 
have symbiotic genes (nod genes) subject to horizontal transfer among $\alpha$ - and some $\beta$-Proteobacteria (Chen et al. 1991; Young and Haukka 1996; Moulin et al. 2001). In contrast, all Frankia sp. strains are closely related with no evidence of dissemination of nodulating ability to related actinobacteria (Fig. 1; Normand et al. 1996; Clawson et al. 2004).

In plants, the capacity to form $\mathrm{N}_{2}$-fixing root nodules occupied by bacteria is retained in a single lineage of angiosperms known as the " $\mathrm{N}_{2}$-fixing clade" (Soltis et al. 1995). Ten families within the Eurosid I clade have members that are nodulated (Soltis et al. 1995; Swensen 1996; Clawson et al. 2004). Only two of the families have members that associate with nodulating proteobacteria, while eight associate with Frankia sp. strains to form the actinorhizal symbiosis (Table 1).

Frankia strains fall into three closely related clusters. Members of each cluster have distinct host ranges (Table 1; Fig. 1). Cluster 1 strains nodulate plants in the Fagales in the Betulaceae and Myricaceae and are often refered to as "Alnus strains" (Normand et al. 1996). A subclade within Cluster 1 is comprised of the narrow host range "Casuarina strains" that under natural conditions nodulate only Casuarina and Allocasuarina species in the Casuarinaceae (Benson et al. 2004). Conversely, Cluster 3 "Elaeagnus strains" are considered to have a broad host range since they nodulate plants from five families in the Fagales and Rosales (Benson et al. 2004). Finally, the "Rosaceous strains" form Cluster 2, which is sister to the others; representatives of this cluster have not been isolated and grown in culture. Cluster 2 strains nodulate plants from four families in the Rosales and Cucurbitales (Benson et al. 2004; Vanden Heuvel et al. 2004).

To gain insight into the evolutionary trajectory followed by these closely related, yet host-range and geographically divergent, Frankia sp. strains, we sequenced and compared the genomes of three isolates, including a narrow host range Casuarina strain, a medium host range Alnus strain, and a broad host range Elaeagnus strain. The results suggest that gene deletion and duplication have occurred to different extents in the genomes during adaptation to host plants and their environments. The concept of genome contraction echoes the changes known to occur

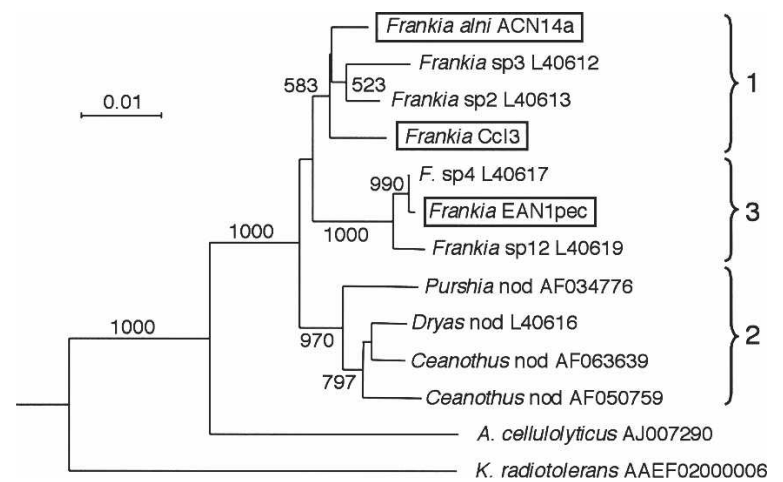

Figure 1. Neighbor-joining (Saitou and Nei 1987) phylogenetic tree calculated with ClustalX 1.83 (Thompson et al. 1997) from 16S rRNA gene sequences. Distances were corrected for multiple substitutions (Kimura 1980); otherwise, default settings were used. Numbers give bootstrap support values from 1000 bootstrapped samples. The outgroup used is Streptomyces coelicolor (NC003888). Accession numbers for the organisms are given after the name and species number as given in Normand and Fernandez (2007). In the case of the unisolated cluster 2 frankiae, the host plant genus from which 16S rRNA gene sequences were amplified is given. Distances in the bar are in substitutions/site. in obligate bacterial pathogens and symbionts (Mira et al. 2001; Ochman and Moran 2001; Moran 2003), but the observation that both contraction and expansion can occur in closely related lineages of facultatively symbiotic soil bacteria in relation to host distribution has not previously been reported.

\section{Results and Discussion}

Actinorhizal plant families emerged in the late Cretaceous $(\sim 100$ million years ago [Mya]) and subsequently adapted to a wide variety of environments (Magallon et al. 1999). Currently, they are globally distributed in climate zones ranging from alpine and subarctic to tropical (Fig. 2) where they add nitrogen and organic material to nutrient-poor soils (Silvester 1976). The native geographical distributions of hosts range from limited in the case of Casuarina sp. to broad in the case of Morella sp. (Fig. 2). The distribution of bacterial symbionts is obviously more difficult to assess, but numerous studies have shown some correlation with plant distribution (for review, see Benson et al. 2004).

Frankia sp. strain HFPCcI3 (CcI3) represents narrow host range Casuarina strains commonly detected in nodules collected from casuarinas in their native Australia (Fig. 2A) and in areas of the world where casuarina trees have been planted as windbreaks or for erosion control (Simonet et al. 1999). Similar strains have not been found in soils in the absence of a suitable host, indicating that the bacteria depend on the plant for their soil propagation (Simonet et al. 1999).

Frankia alni strain ACN14a (ACN) represents Alnus strains that are globally distributed in soils regardless of the presence of a suitable host plant (Benson et al. 2004). This ubiquity parallels the distribution of host plants from the Betulaceae and Myricaceae that have a combined native range spanning all continents except Australia (Table 1; Fig. 2B).

Frankia sp. strain EAN1pec (EAN) represents broad host range Elaeagnus strains that are also globally distributed in soils with or without host plants (Benson et al. 2004). Cognate hosts are the most diverse and have the widest distribution with representatives on all continents including Australia (Table 1; Fig. 2C).

The strains used in this study have $16 \mathrm{~S}$ rRNA gene sequences that are $97.8 \%$ identical between $\mathrm{ACN}$ or $\mathrm{CCI} 3$ versus EAN, and 98.9\% identical between ACN and CcI3 (Fig. 1). This similarity level is frequently observed among bacteria from the same species (Wayne et al. 1987; Gevers et al. 2005), and is typical of the similarity levels found within the genus Frankia (Fig. 1; Clawson et al. 2004).

\section{Genome characteristics}

The genomes from ACN and CcI3 have been finished, and that from EAN has been rendered in a single scaffold with some gaps corresponding to regions that have proven difficult to resolve due to sequence repeats and high GC content (Table 2). Nevertheless, unlike Streptomyces (Bentley et al. 2002), all three genomes are circular as demonstrated directly from their sequences (Fig. 3). None of the strains have yielded independently replicating plasmids. Unlike what is observed for obligate symbionts, the coding capacity of the genomes remains quite high at $89 \%$ for ACN, $84 \%$ for $\mathrm{CcI} 3$, and $86 \%$ for EAN.

The most striking difference between the three genomes is their sizes, ranging from $5.43 \mathrm{Mb}$ for CcI3 (4499 protein-coding sequences [CDS]), to $7.50 \mathrm{Mb}$ for ACN (6786 CDS), to $9.04 \mathrm{Mb}$ for

\section{Genome Research}

www.genome.org 
Table 1. Relationship between actinorhizal plants and groups of Frankia strains ${ }^{\mathrm{a}}$

\begin{tabular}{|c|c|c|c|c|}
\hline Order ${ }^{b}$ & Family (\#nod/\#gen) ${ }^{c}$ & Genus (No. species) & Geographical distribution & Frankia cluster $^{\mathrm{d}}$ \\
\hline \multirow[t]{8}{*}{ Fagales } & Betulaceae $(1 / 6)$ & Alnus (30) & N. temperate, SA, N. Africa, Asia & $1,(3)$ \\
\hline & \multirow[t]{3}{*}{ Myricaceae (3/4) } & Comptonia (1) & Eastern NA & 1,3 \\
\hline & & Morella (20) & Cosmopolitan, not Australia or Mediterranean & 1,3 \\
\hline & & Myrica (2) & Circumpolar & $1(3)$ \\
\hline & \multirow[t]{4}{*}{ Casuarinaceae (4/4) } & Allocasuarina (58) & Australia & 1 \\
\hline & & Casuarina (17) & Australia & $1(3)$ \\
\hline & & Ceuthostoma (1) & Malesia & ND \\
\hline & & Gymnostoma (10) & Malaysia to W. Pacific & 3 \\
\hline \multirow[t]{13}{*}{ Rosales } & \multirow[t]{3}{*}{ Elaeagnaceae (3/3) } & Elaeagnus (10) & Europe, Asia, NA & 3 \\
\hline & & Hippophae (2) & Temperate Eurasia & 3 \\
\hline & & Shepherdia (2) & NA & 3 \\
\hline & \multirow{6}{*}{ Rhamnaceae (6/55) } & Ceanothus (55) & Western NA & $2,(3)$ \\
\hline & & Colletia (17) & Southern SA & 3 \\
\hline & & Discaria (15) & Southern SA, Australia, New Zealand & 3 \\
\hline & & Kentrothamnus (1) & Southern SA & 3 \\
\hline & & Retanilla (4) & Southern SA & 3 \\
\hline & & Trevoa (1) & Southern SA & 3 \\
\hline & \multirow[t]{4}{*}{ Rosaceae $(4 / 100)$} & Cercocarpus (6-10) & Western NA & 2 \\
\hline & & Chamaebatia (2) & Western NA & 2 \\
\hline & & Dryas (2-3) & Circumboreal, arctic-alpine & 2 \\
\hline & & Purshia (8) & Western NA & 2 \\
\hline \multirow[t]{2}{*}{ Cucurbitales } & Coriariaceae $(1 / 1)$ & Coriaria (5-20) & $\begin{array}{l}\text { Mexico to SA, W. Mediterranean, New Zealand, } \\
\text { Papua New Guinea, S.E. Asia }\end{array}$ & 2 \\
\hline & Datiscaceae $(1 / 1)$ & Datisca (2) & Western NA, S. Asia & 2 \\
\hline
\end{tabular}

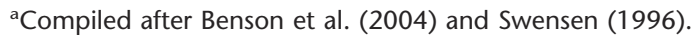

bAccording to the classification of the Angiosperm Phylogeny Group (APG 1998); all of these orders fall in the "Eurosid I" group of eudicots.

'The number of genera within the family is listed along with the number of genera nodulated. Not all genera within a family are capable of nodulation.

dThe Frankia cluster refers to the clusters of Frankia strains in Figure 1 typically found in root nodules of each plant genus. 1, alder and casuarina strains; 3 , elaeagnus strains; 2, rosaceous strains; ND, not determined; (3) indicates rare detection of an elaeagnus strain in a nodule or in surface layers of a nodule (Benson et al. 2004).

(NA) North America; (SA) South America.

EAN (7976 CDS) (Table 2). On a total DNA basis, this range is the largest reported for any group of free-living prokaryotes related at the $98 \%-99 \% 16 \mathrm{~S}$ rRNA sequence level described to date. The smallest genome belongs to the narrow host range and geographically limited representative $\mathrm{CcI} 3$, and the largest is from strain EAN, which belongs to the broadest host range group. This size correlation raises the hypothesis that genome size and content is driven by the host range and biogeography of the symbiosis. We addressed this hypothesis through comparative analysis of the genomes' contents and structures to determine how the disparate sizes have come about.

The genome maps shown in Figure 3 indicate that the patterns of synteny are quite similar, with synteny decreasing as the terminus of replication is approached, corresponding to a high degree of gene rearrangement, duplication, or deletion in this region. Indeed, much of the size differences can be accounted for by expansion in this area of the genomes of EAN and ACN. Genes related to symbiosis shown in Figure 3 include those encoding nitrogenase (nif), uptake hydrogenase (hup), and squalene hopane cyclase $(s h c)$ involved in bacteriohopane biosynthesis. Only one gene similar to the common nodulation genes in rhizobia has been found in each strain, but with a general function prediction and relatively low BLAST scores (the product of FRAAL4911, annotated as a chitin deacetylase, resembles NodB from Rhizobium $s p$. N33 with a score of $3 \mathrm{e}^{-34}$ but also resembles similar proteins from many other organisms, mainly Bacillus sp.). Little is known about the genetic basis of the actinorhizal symbiosis, but it is clearly very different from that known to exist among the nodulating proteobacteria.

\section{IS elements and prophage}

Insertion elements, transposases, integrated phage, and plasmids tend to reflect the degree of plasticity of genomes (Frost et al. 2005). In the three Frankia strains, integrases plus transposases comprise $\sim 0.6 \%$ (46) of the ACN CDS, $4.1 \%$ (187) of the CcI3 CDS, and 3.4\% (269) of the EAN CDS (Table 3). Such elements tend to cluster in regions where there is loss of synteny between genomes (Fig. 3). CcI3 has a higher average density of mobile elements (34 per $\mathrm{Mb}$ ) than EAN (30 per $\mathrm{Mb}$ ), and both have a much higher density than ACN (6 per $\mathrm{Mb}$ ). Indeed, of the 33 transposase genes identified in ACN, all but four are found in the same context in $\mathrm{CcI} 3$, and all but six are in EAN, suggesting that such genes in $\mathrm{ACN}$ have been inactive for at least the 55 million years since the genomes diverged (Normand et al. 1996; Clawson et al. 2004). Examining regions surrounding phage integrases, we estimate that prophage contribute $0.4 \%, 11.7 \%$, and $7.1 \%$ of the CDS of ACN, CcI3, and EAN, respectively. Overall, EAN and CcI3 have had far more dynamic genomes than ACN in their recent history, and this plasticity, conferred by IS elements and phage moving into and out of the genomes, may in large part have driven the size differences observed.

\section{Gene deletions}

To examine how the three genomes have evolved to have such different sizes, we used the order of divergence of the three strains (Fig. 1) to estimate how the genome size differences reflect gene deletion, duplication, and acquisition. Using the approximation of $50 \mathrm{Myr}$ per $1 \%$ divergence in the $16 \mathrm{~S}$ rRNA genes 


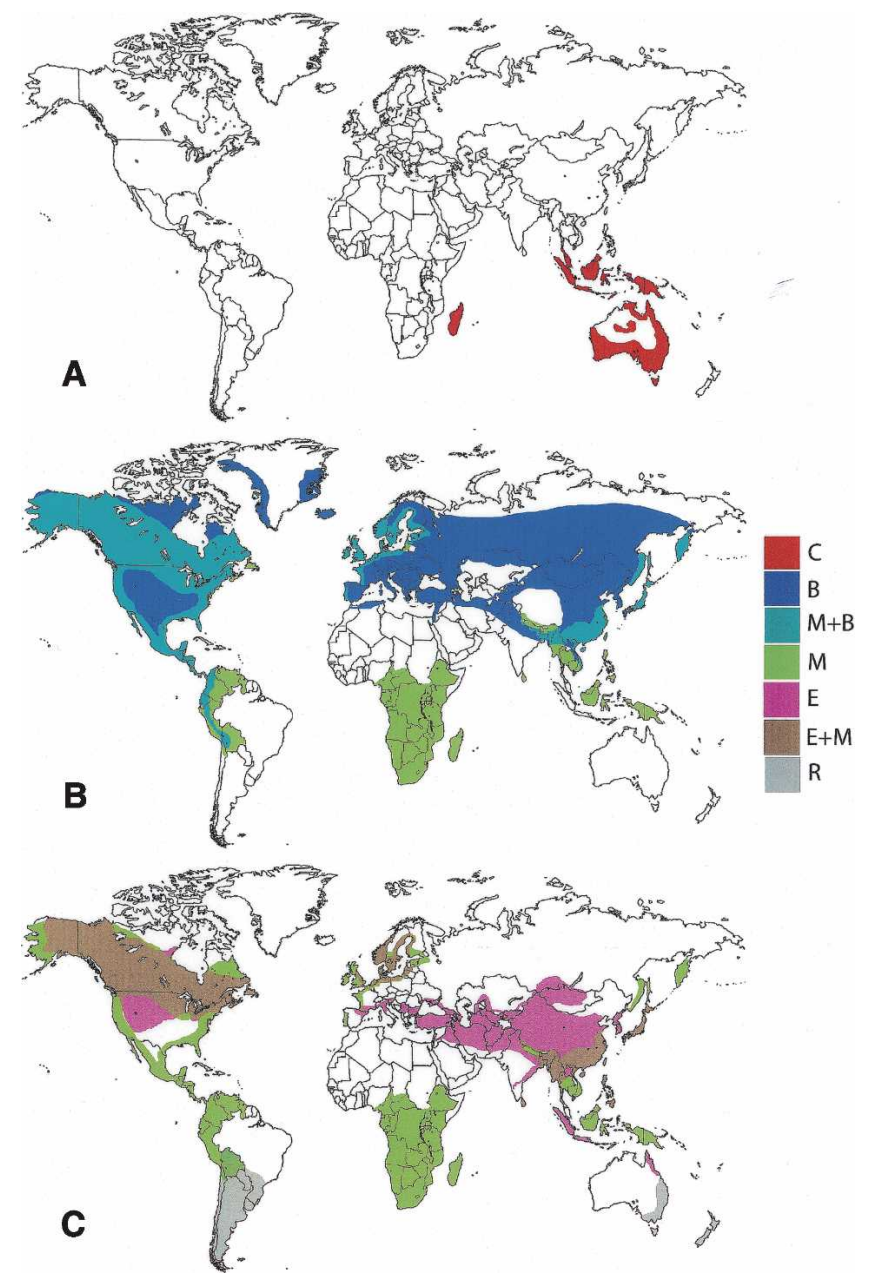

Figure 2. Present-day native distribution of actinorhizal plant hosts. $(A)$ Distribution of plant hosts for $\mathrm{Ccl} 3$, including Casuarina and Allocasuarina of the Casuarinaceae (C). (B) Distribution of plant hosts for ACN, including Alnus sp. in the Betulaceae (B) and Myricaceae (M) and their overlap $(\mathrm{M}+\mathrm{B})$. (C) Distribution of plant hosts for EAN including members of the Elaeagnaceae (E), Myricaceae (M), and the actinorhizal Tribe Colletieae of the Rhamnaceae in South America, Australia, and New Zealand (R). Elaeagnaceae and Myriceae (E+M) overlap in some areas. Maps were drawn with information from Silvester (1977) and from the Missouri Botanical Garden Web site (www.mobot.org).

(Ochman et al. 1999), the clade containing EAN diverged an estimated 115 Mya from the clade containing CcI3 and ACN, which diverged from each other about 55 Mya (Fig. 1). Therefore, orthologous genes present in ACN and EAN but absent in CcI3 may be assumed to have been lost from CcI3 after it diverged from ACN. A similar approach can be used for identifying deleted genes from ACN. However, genes absent from EAN, but present in the other two strains, could either have been lost in EAN or acquired by horizontal gene transfer (HGT) in the progenitor of ACN and CcI3.

Defining the presence and absence of orthologs by using a reciprocal best BLAST hit criterion with an E-value threshold of $10^{-4}$, we find that 1054 genes present in both ACN and EAN are not found in CcI3 (Table 3). Similarly, 466 genes are missing from ACN, and 555 are missing from EAN. The most logical explanation for the smaller number of genes missing in EAN and ACN versus $\mathrm{CcI} 3$ is an accelerated rate of gene loss in $\mathrm{CcI} 3$ over the past 55 Myr since diverging from a common ancestor with ACN. Since EAN has had longer to lose genes, its apparent rate of loss is lower than that of either ACN or CcI3. The number deleted is underestimated in all cases since genes deleted from two of the three strains would appear as strain specific or horizontally transferred (below).

A BlastClust analysis was done to categorize deleted genes using $30 \%$ sequence identity over $52 \%$ of the length. This analysis indicated that some categories of genes were preferentially deleted over others. Genes annotated as hypothetical, conserved hypothetical, or of unknown function account for about onethird of the total (28\%-34\%) lost in each genome (Table 4). CcI3 is missing the most genes in all categories shown in Table 4 except for integrases and transposases; the latter have been especially reduced in ACN. In CcI3, genes involved in transport (including $\mathrm{ABC}$ transporters, solute-binding-dependent transport proteins), regulatory proteins (including genes in the categories TetR, IclR, LuxR, MarR, MerR), dehydrogenases, amidotransferase, oxygenases, and many hypothetical proteins, proteins of unknown function, and conserved hypothetical proteins have been lost. In short, genes encoding the capacity to scavenge and metabolize substrates from the environment have been reduced in CcI3.

Several genes lost by CcI3 are concerned with metabolic activities of potential importance to survival or symbiosis. These include genes encoding the DNA repair enzymes AP endonuclease, photolyase, DNA-formamidopyrimidine glycosylase, DNA alkylation repair, and RadC; two cellulases that might be involved in survival or infection; gas vesicle proteins whose loss could signal adaptation to dry environments where Casuarina sp. grow; general metabolism enzymes (NAD-dependent glutamate dehydrogenase, PEP carboxylase); and a large number of regulatory and solute transport proteins. Among the latter, there is only one iron siderophore gene cluster in $\mathrm{CcI} 3$ as compared with two in ACN and three in EAN. More directly related to symbiosis, CcI3 has lost one of the two copies of the shc (squalene hopene cyclase) genes involved in synthesizing bacteriohopane lipids that comprise the envelope of Frankia vesicles and provide protection for nitrogenase against oxygen. Unlike ACN and EAN, oxygen protection is conferred by secondary plant cell walls when CcI3 is in symbiosis (Berg and McDowell 1988), perhaps making bacteriohopane synthesis less of a priority.

In general, the classes of genes lost by CcI3 (DNA repair, metabolic enzymes, regulatory proteins) resemble those known to be lost by bacterial endosymbionts of animals (Mira et al.

Table 2. Summary of genome characteristics ${ }^{\mathrm{a}}$

\begin{tabular}{lccc}
\hline & $\begin{array}{c}\text { ACN } \\
\text { (finished) }^{\mathbf{b}}\end{array}$ & $\begin{array}{c}\text { Ccl3 } \\
\text { (finished) }\end{array}$ & $\begin{array}{c}\text { EAN (draft-1 } \\
\text { scaffold) }\end{array}$ \\
\hline Size in bp & $7,497,934$ & $5,433,628$ & $9,035,218$ \\
Predicted CDS & 6786 & 4499 & 7976 \\
Genes in COGs & $4502(67 \%)$ & $2564(57 \%)$ & $4815(60 \%)$ \\
tRNA & 46 & 46 & 47 \\
rRNA (5S-16S-23S) & 2 & 2 & 3 \\
\%G+C & 72.83 & 70.07 & 70.94 \\
Accession & CT573213 & CP000249 & AAll00000000 \\
\hline
\end{tabular}

${ }^{a}$ Numbers are derived from the accession numbers indicated as of November 13, 2006.

${ }^{b}$ Numbers are from http://www.genoscope.cns.fr.

cNumbers are from accessions indicated at http://www.ncbi.nlm.nih.gov except for the genes in COGs for EAN, listed at http://www.jgi.doe.gov.

\section{Genome Research}




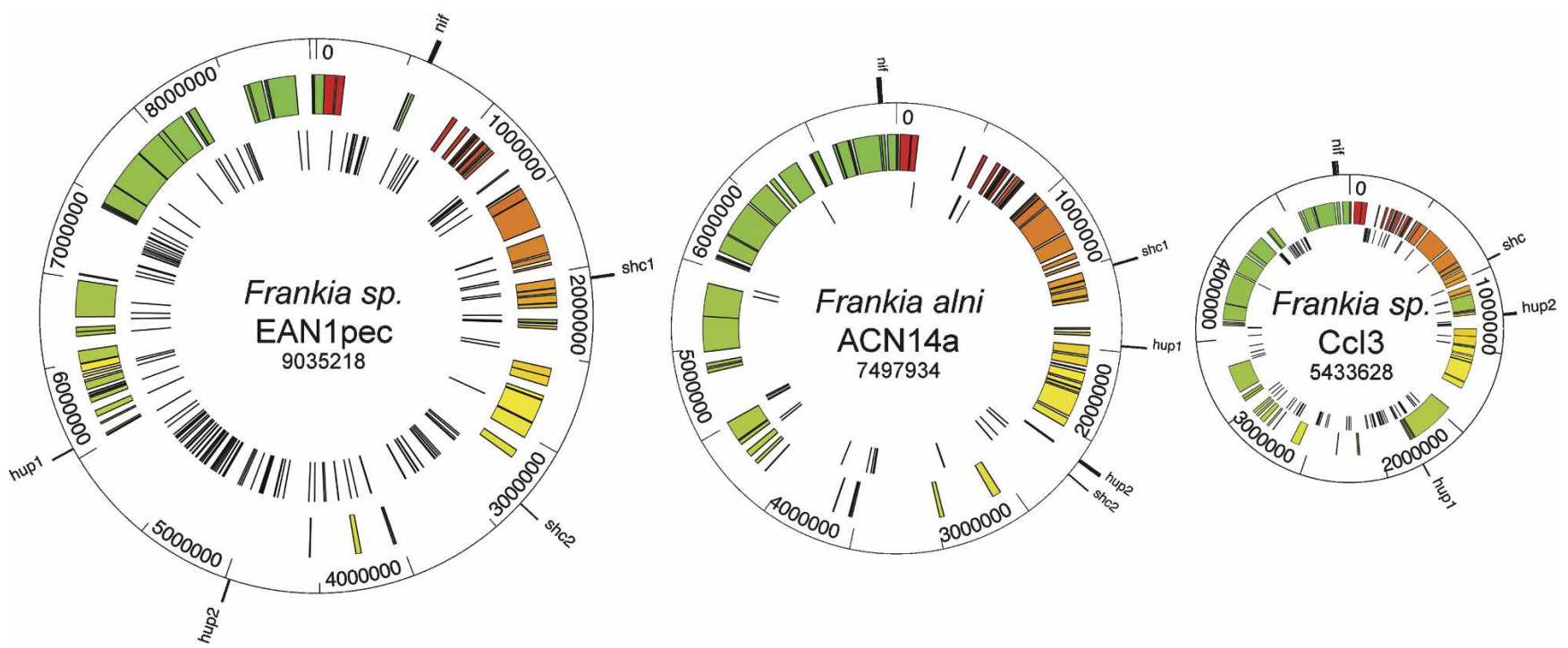

Figure 3. Genome maps of the three Frankia strains. Circles, from the outside in, show (1) gene regions related to symbiosis including shc1, hup2, hup1, and nif; (2) the coordinates in $\mathrm{Mb}$ beginning at $0=$ oriC; (3) regions of synteny (syntons) calculated as a minimum of five contiguous genes present in all strains with an identity $>30 \%$ over $80 \%$ of the length of the shortest gene (syntons are tagged with a spectrum-based [red-yellow-green] color code standardized on ACN to indicate regions where syntons have moved in the other strains); (4) IS elements and transposases. Circles were drawn using GenVision Software from DNAStar.

2001; Ochman and Moran 2001), and indicate that CcI3 is evolving toward a greater dependence on its host. However, CcI3 can still grow on minimal medium, so such strains have not yet been committed to an obligate symbiotic existence.

\section{Gene duplication, acquisition, and ORFans}

Gene duplication is a major means by which soil bacteria adapt to new niches, or to the availability of new substrates (Francino 2005; Konstantinidis and Tiedje 2005). Gene acquisition is known to be similarly involved in bacterial adaptation to new environments, particularly in the emergence of pathogens (Mira et al. 2001; Ochman and Moran 2001) and in the evolution of mutualistic bacteria in the legume symbiosis (Young and Haukka 1996; Chen et al. 2001; Moulin et al. 2004). Frankia symbionts have adapted both to living in diverse soils in most parts of the world and to living in root nodules from phylogenetically diverse angiosperms.

We defined duplicates as having the lowest BLAST E-value with a gene from the same genome when compared with genomes from other Frankia strains, Acidothermus and Kineococcus,

Table 3. Summary of genes involved in size differentiation of the three Frankia strains

\begin{tabular}{|c|c|c|c|}
\hline Category & $\mathrm{ACN}$ & $\mathrm{Ccl3}$ & EAN \\
\hline Deleted genes & 466 & 1054 & 555 \\
\hline Duplicated genes & $512(7.5 \%)$ & $444(9.8 \%)$ & $1355(18.5 \%)$ \\
\hline $\begin{array}{l}\text { Strain-specific genes } \\
\text { (SSGs) }\end{array}$ & 709 (10.4\%) & $420(9.3 \%)$ & $934(11.7 \%)$ \\
\hline ORFans & $854(12.5 \%)$ & $158(3.5 \%)$ & $355(4.9 \%)$ \\
\hline Transposases & $33(0.4 \%)$ & $155(3.4 \%)$ & $195(2.4 \%)$ \\
\hline Integrases & $13(0.2 \%)$ & $32(0.7 \%)$ & $74(0.9 \%)$ \\
\hline
\end{tabular}

Deleted genes, duplicated genes, ORFans (no hits in any database), and strain-specific genes (SSG; hits in databases but not in the other two Frankia strains) were detected as described in the text. The number of genes annotated as transposases and inactivated derivatives plus integrases were annotated as described. both close relatives to Frankia in the Frankineae, Streptomyces spp., and the NR (non-redundant) database. Using this approach, $7.5 \%$ (512) of the ORFs in ACN, 9.8\% (444) in CcI3, and 18.5\% (1355) in EAN could be considered duplicates of other genes in the same genomes (Table 3). Core metabolic genes are generally not duplicated, a differential amplification noted in other bacteria (Francino 2005; Konstantinidis and Tiedje 2005). Surprisingly, CcI3, which has sustained strong reducing evolutionary pressures, nevertheless had a slightly higher percentage of duplicates than $\mathrm{ACN}$, an observation that is accounted for by the proliferation of transposase genes in CcI3 (Tables 3, 5). Gene duplication has thus enlarged the EAN genome to a greater ex-

Table 4. Categories of deleted genes assessed by BlastClust analysis

\begin{tabular}{lrrr}
\hline General category & Ccl3 & ACN & EAN \\
\hline Hypothetical, conserved hypothetical, & & & \\
$\quad$ unknown function & 289 & 158 & 176 \\
Transport-associated & 113 & 33 & 28 \\
Regulatory & 95 & 21 & 35 \\
Short-chain dehydrogenase/reductase & 32 & 4 & 4 \\
Acyl-CoA dehydrogenase-like & 19 & 3 & 1 \\
Alkanesulfonate monooxygenase & 17 & 0 & 0 \\
AMP-dependent synthetase and ligase & 14 & 3 & 2 \\
Protein kinase & 12 & 2 & 6 \\
Amidohydrolase & 13 & 1 & 1 \\
Enoyl-CoA hydratase/isomerase & 10 & 1 & 2 \\
L-carnitine dehydratase/bile acid & & & \\
inducible protein F & 9 & 2 & 2 \\
Alcohol dehydrogenase GroES-like & 7 & 1 & 2 \\
Cytochrome P450 & 8 & 5 & 3 \\
Transposases & 7 & 33 & 11 \\
Integrases & 3 & 7 & 6 \\
Other & 406 & 192 & 276 \\
\hline
\end{tabular}

Deleted genes are defined as genes present in two of the three strains as assessed by BLAST hits below a cutoff of $10^{-4}$ but absent in the third. The general categories correspond to the major groups identified by a BlastClust analysis of missing genes. 
Table 5. Top 20 families of duplicated genes in each Frankia strain assessed by BlastClust analysis

\begin{tabular}{|c|c|c|c|c|c|}
\hline \multicolumn{2}{|l|}{ ACN } & \multicolumn{2}{|l|}{$\mathrm{Ccl} 3$} & \multicolumn{2}{|l|}{ EAN } \\
\hline Annotated function & \# & Annotated function & \# & Annotated function & \# \\
\hline $\begin{array}{l}\text { Putative serine/threonine protein } \\
\text { kinase }\end{array}$ & 22 & Transposase, IS4 & 31 & $\begin{array}{l}\text { Short-chain } \\
\text { dehydrogenase/reductase SDR }\end{array}$ & 49 \\
\hline $\begin{array}{l}\text { Putative oxidoreductase, } \\
\text { short-chain } \\
\text { dehydrogenase/reductase family }\end{array}$ & 20 & Transposase IS66 & 15 & Integrase, catalytic region & 48 \\
\hline $\begin{array}{l}\text { Hypothetical protein; putative } \mathrm{HNH} \\
\text { endonuclease domain }\end{array}$ & 17 & Transposase, IS4 & 14 & $\begin{array}{l}\text { ABC-type branched-chain amino } \\
\text { acid transport, periplasmic } \\
\text { component }\end{array}$ & 32 \\
\hline $\begin{array}{l}\text { Hypothetical protein; putative } \\
\text { dehydrogenase }\end{array}$ & 16 & Transposase & 12 & Transposase, IS605 OrfB & 27 \\
\hline $\begin{array}{l}\text { Putative oligopeptide transport } \\
\text { protein (ABC superfamily) }\end{array}$ & 14 & $\begin{array}{l}\text { Regulatory protein, } \\
\text { MerR:Recombinase }\end{array}$ & 11 & Acyl-CoA dehydrogenase-like & 23 \\
\hline $\begin{array}{l}\text { Putative SAM-dependent } \\
\text { methyltransferases }\end{array}$ & 13 & $\begin{array}{l}\text { Twin-arginine translocation } \\
\text { pathway signal }\end{array}$ & 7 & Cytochrome P450 & 22 \\
\hline $\begin{array}{l}\text { Putative alpha-methylacyl-CoA } \\
\text { racemase }\end{array}$ & 10 & Transposase, IS4 & 7 & Luciferase-like & 21 \\
\hline $\begin{array}{l}\text { Branched-chain amino acid } A B C \\
\text { transport, binding protein }\end{array}$ & 10 & $\begin{array}{l}\text { Transposase and inactivated } \\
\text { derivatives-like }\end{array}$ & 7 & Integrase, catalytic region & 20 \\
\hline $\begin{array}{l}\text { Hypothetical protein; putative } \\
\text { signal peptide }\end{array}$ & 9 & $\begin{array}{l}\text { Transposase, } \\
\text { IS111A/IS1328/IS1533:Transposase } \\
\text { IS116/IS110/IS902 }\end{array}$ & 7 & Amidohydrolase 2 & 20 \\
\hline $\begin{array}{l}\text { Putative non-ribosomal peptide } \\
\text { synthetase }\end{array}$ & 8 & $\begin{array}{l}\text { Transposase (probable), } \\
\text { IS891/IS1136/IS1341:Transposase, } \\
\text { IS605 OrfB }\end{array}$ & 7 & $\begin{array}{l}\text { Extracellular solute-binding protein, } \\
\text { family } 5\end{array}$ & 19 \\
\hline $\begin{array}{l}\text { Branched-chain amino acid } \\
\text { transport protein (ABC } \\
\text { superfamily) }\end{array}$ & 6 & Putative IS630 family transposase & 7 & $\begin{array}{l}\text { Membrane-bound lytic murein } \\
\text { transglycosylase B-like }\end{array}$ & 17 \\
\hline $\begin{array}{l}\text { Conserved hypothetical protein; } \\
\text { putative amidohydrolase domain }\end{array}$ & 6 & Hydantoinase/oxoprolinase & 7 & GGDEF domain & 14 \\
\hline $\begin{array}{l}\text { Putative GntR-family transcriptional } \\
\text { regulator }\end{array}$ & 6 & ATP-binding region, ATPase-like & 6 & Putative transposase & 13 \\
\hline $\begin{array}{l}\text { Putative TetR-family transcriptional } \\
\text { regulator }\end{array}$ & 5 & Putative O-methyltransferase & 5 & Transposase, IS4 & 13 \\
\hline $\begin{array}{l}\text { Hypothetical protein; putative } \\
\text { dibenzothiophene desulfurization }\end{array}$ & 5 & $\begin{array}{l}\text { Putative plasmid replication } \\
\text { initiator protein }\end{array}$ & 5 & $A B C$ transporter related & 12 \\
\hline Cytochrome P450 & 5 & Transposase, IS4 & 4 & Regulatory protein, LuxR & 12 \\
\hline Hypothetical protein & 5 & Hypothetical protein & 4 & RNA-directed DNA polymerase & 11 \\
\hline Putative monooxygenase & 4 & Amino acid adenylation & 3 & $\begin{array}{l}\text { Phenylpropionate } \\
\text { dioxygenase/related } \\
\text { ring-hydroxylating dioxygenases }\end{array}$ & 11 \\
\hline Hypothetical protein & 4 & Putative DNA-binding protein & 3 & $\begin{array}{l}\text { Taurine catabolism dioxygenase } \\
\text { TauD/TfdA }\end{array}$ & 11 \\
\hline Putative aldehyde dehydrogenase & 4 & Hypothetical protein & 3 & Regulatory protein, TetR & 11 \\
\hline
\end{tabular}

The top 20 categories of duplicated genes were defined by a BlastClust analysis of a data set comprised of all duplicates. Duplicates were defined as having the best BLAST score of another gene within the same genome relative to genes within NR plus the other Frankia strains, Acidothermus, Kineococcus, and Streptomyces spp. with a maximum cutoff of $10^{-4}$.

tent than the genomes of ACN or CcI3. Most of the duplicated genes seem to be located near the replication terminus in all strains. Localization of contingency genes to the terminus has been observed in the linear genomes of Streptomyces sp. and in other large genomes (Bentley et al. 2002; Ikeda et al. 2003).

To assess the types of genes duplicated, a BlastClust (NCBI) analysis was done to cluster proteins using a standard of $25 \%$ identity over at least $40 \%$ of the length of the amino acid sequence. A more stringent analysis using 30\% identity over $52 \%$ of the sequence gave essentially the same results. In the top 20 duplicated gene families in CcI3, 116 out of 165 (70\%) genes belong to several classes of transposases and genes associated with prophages (Table 5). In ACN, no transposases are found in the 151 genes in the top 20 families; instead, genes annotated as serine-threonine protein kinases, short-chain dehydrogenases/ reductases, endonucleases, SAM-dependent methyltransferases, transport proteins, and a variety of dehydrogenases are duplicated. In EAN, 132 out of 406 (32.5\%) genes are associated with integrases, transposases, or reverse transcriptases in the top 20 families, with the remainder annotated as short-chain dehydrogenase/reductases, cytochrome P450s, transport proteins, regulatory proteins, and dioxygenases.

In sum, EAN has the most duplicated genes in all categories, including those whose products are associated with metabolic processes as well as mobile genetic elements. ACN has the fewest duplicates, and those are of genes involved in general metabolism. Finally, a large portion of all duplicates in CcI3 (33\% overall) is of transposases. In all strains, the majority of duplicates appeared as two copies of a single gene.

Strain-specific genes (SSGs) include genes lost by two of the three Frankia strains plus genes that have no hits in databases (ORFans). Such genes could also have been horizontally transferred from other bacteria. Using a permissive threshold (Evalue $\leq 10^{-4}$ ) between the genomes, and allowing self-genome hits to eliminate duplication, we found that $23 \%$ (1563) of the genes in $\mathrm{ACN}, 12.8 \%(578)$ in $\mathrm{CcI} 3$, and $17.7 \%$ (1289) in EAN

\section{Genome Research}

www.genome.org 
have no clear homologs in the other two genomes. Of those, 854 (12.5\%) in ACN, 158 (3.5\%) in CcI3, and 355 (4.9\%) in EAN were ORFans with no hits in NR, or the related Acidothermus, Kineococcus, or Streptomyces spp. genomes. The higher number and percentage of ORFans in ACN may reflect a lower evolutionary pressure to eliminate non-essential genes, a characteristic also reflected in its having the fewest deleted genes overall (Table 3).

\section{Conclusions}

We have shown that the unusual size divergence displayed by the Frankia genomes has arisen by the processes of deletion, duplication, and retention/acquisition operating in all strains but to different extents (Table 3 ). These processes have driven the genomes in different directions, reducing that of $\mathrm{CcI} 3$, expanding that of EAN, and keeping ACN relatively stable. The results of these broad comparisons lead us to propose a link between the biogeographic history of the actinorhizal plants and the genome evolution of the bacterial symbionts.

Evidence from ecological (Zimpfer et al. 1997), molecular ecological (Simonet et al. 1999), physiological (Sellstedt 1995), and now genomic studies indicates that Casuarina strains represented by $\mathrm{CcI} 3$ have evolved to become specialists with reduced genomes. Unlike Alnus and Elaeagnus strains, they have not been detected by trapping experiments in soils outside the native ranges of their host plants (Zimpfer et al. 1997; Simonet et al. 1999), and they infect a narrow spectrum of hosts (Fig. 2A; Table 1). Genome reduction is well documented in obligate pathogens and obligate symbionts in plants and animals (Mira et al. 2001; Ochman and Moran 2001; Moran 2003; Batut et al. 2004), and in some free-living cyanobacterial Prochlorococcus sp. (Dufresne et al. 2005). Genome reduction has not been described in bacterial facultative symbionts that also exist free-living in the soil; indeed, this is a most unexpected finding.

We suggest that a likely explanation for genome reduction in CcI3 is its geographic and symbiotic isolation in Australia and the Pacific islands, paralleling its host plants' isolation beginning 100-65 Mya. Casuarinaceae species emerged as part of the flora of Gondwana as evidenced by fossils in New Zealand and South America that today are outside the native range (Campbell and Holden 1984). These plants, and their bacterial symbionts, coadapted to a hotter, drier climate as Australia split from Antarctica and moved north toward the equator. Present-day Casuarina strains live in locales where the soil biotic capacity is reduced and actinorhizal host diversity is limited.

In contrast, plants infected by Elaeagnus strains have a global distribution (Fig. 2C) with ancestral origins in both Gondwana (Gymnostoma in the Casuarinaceae in Western Oceania, actinorhizal Colletieae in the Rhamnaceae) and Laurasia (Elaeagnaceae, Myricaceae). Such plants occupy a wide range of soil types and climates. Genome expansion by gene duplication and divergence is a mechanism used by soil bacteria to exploit new niches and new substrates (Francino 2005; Konstantinidis and Tiedje 2005), and may be inferred to have occurred in the ancestors of EAN as they and their hosts coadapted to new and diverse soils. Indeed, the types of genes duplicated are largely involved in introducing substrates into central metabolic pathways.

The genome of ACN appears more stable than those of $\mathrm{CcI} 3$ and EAN, in the sense that it has few transposases and integrases; it also has lost the fewest genes by deletion, has the lowest proportion of duplicated genes, and retains the most strain-specific genes, including ORFans. Its stability may reflect its host range focused on the ancient lineages in the Betulaceae and Myricaceae leading to high soil abundance and relatively strong genome homogenization. Its host plants have the longest fossil record of the $\mathrm{N}_{2}$-fixing clade (Magallon et al. 1999), and have inhabited similar and milder environments in northern latitudes since appearing in Laurasia during the late Cretaceous (Crane 1989).

Taken together, the gene contents of the three Frankia strains appear to reflect the biogeographic history of the host plants they infect, and as such may provide the first example of differential genome contraction and expansion occurring in closely related facultatively symbiotic soil bacteria that may be linked to the evolutionary history of their hosts on a global scale.

\section{Methods}

\section{Strains}

CcI3 was isolated from Casuarina cunninghamiana plants growing in a greenhouse at Harvard Forest in Petersham, MA (Zhang et al. 1984) on soils coming from its original provenance. ACN was isolated initially from Alnus viridis subsp. crispa plants in Tadoussac, Quebec (Normand and Lalonde 1982; Benson et al. 2004). Strain EAN was isolated from field nodules of $E$. angustifolia growing in Ohio (Lalonde et al. 1981).

\section{Genome sequencing, assembly, and finishing-Ccl3 and EANIpec}

We sequenced the three genomes of Frankia strains ACN14a, CcI3, and EAN1pec using a shotgun approach. The genomes of Frankia strains CcI3 and EAN1pec were sequenced at the Joint Genome Institute (JGI) using a combination of 3-kb, 8-kb, and 40-kb (fosmid) DNA libraries for each strain. Draft assemblies were based on 82,561 total reads for CcI3 and 125,615 total reads for EAN1pec. The different libraries provided $4.6 \times(3-\mathrm{kb}), 4.1 \times$ (8-kb), and $0.5 \times$ (fosmids) coverage of $\mathrm{CcI} 3$ and $4.0 \times(3-\mathrm{kb})$, $3.4 \times(8-\mathrm{kb})$, and $0.6 \times$ (fosmids) coverage of EAN1pec. End sequencing and fingerprinting of fosmid clones aided in assembly verification, determination of gap sizes, and ordering and orientation of scaffolds beyond assembly gaps.

Sequencing gaps were closed mainly by primer walking on plasmid and fosmid subclone templates. In cases where no acceptable template was available, PCR products were made and sequenced using customized primers. Gaps resulting from hardto-sequence DNA structures had to be covered using special chemistries and protocols developed in-house. Mis-assemblies were identified and corrected by means of clone pairing; these primarily occurred due to long repeats (rRNAs, IS elements). Over-collapsing of repeat copies often resulted in pseudo-gaps in the assembly, which could not be closed by routine primer walking. Each one of those had to be filled in using one of the following two methods. Small pseudo-gaps were closed using the editing features of CONSED (Gordon et al. 1998), by locating and placing appropriate reads individually into their proper repeat copy. Long pseudo-gaps and long misassembled repeats $(>2 \mathrm{~kb})$ had to be isolated and separately assembled. Only consistent, partially unique clone-mates would be allowed in those subassemblies. After verifying the subassembly's integrity and primerwalking over the poorly covered regions, the isolated contigs were reintroduced into the main assembly as "fake reads," that is, single continuous long sequences reflecting the correctly assembled repeat copy.

All other general aspects of library construction, sequencing, and automated annotation were carried out as previously de- 
scribed for bacterial genomes sequenced at the JGI (Chain et al. 2003). In addition, predicted coding sequences are subject to manual analysis using the Integrated Microbial Genomes (IMG) annotation pipeline. Detailed information about genome annotation and other genome properties can be obtained at http:// img.jgi.doe.gov (Markowitz et al. 2006).

\section{Genome sequencing, assembly, and annotation-ACN14a}

For ACN14a, four libraries were made: Two plasmid libraries of 3 $\mathrm{kb}$ and $10 \mathrm{~kb}$, obtained by mechanical shearing, were constructed at Genoscope (Evry, France) into pcDNA2.1 (Invitrogen) and into the pCNS home vector (pSU18 modified, Bartolome et al. 1991), respectively. Two BAC libraries of an average insert size of $104 \mathrm{~kb}$ were constructed at Clemson University Genomics Institute (CUGI) by enzymatic digestion (EcoRI and HindIII) into pCUGIBAC1 (Luo and Wing 2003). Plasmid and BAC DNAs were purified and end-sequenced using dye-terminator chemistry on ABI3730xl DNA Analyzer sequencers. We generated 150,890 sequences from both ends of genomic clones from the four libraries.

The Phred/Phrap/Consed software package (www.phrap. com) was used for sequence assembly and quality assessment (Ewing and Green 1998; Ewing et al. 1998; Gordon et al. 1998). A total of 8956 additional reactions were necessary to close gaps, generally with the transposing method (Entranceposon, Finnzymes, Espoo, Finland) and to raise the quality of the finished sequence. The validity of the final sequence was assessed by comparing the restriction enzyme pattern deduced from the sequence to the experimentally observed restriction pattern obtained by digestion of genomic DNA. After a first round of annotation, regions of lower quality as well as regions with putative frame-shifts were resequenced from PCR amplification of the dubious regions.

Using the AMIGene software (Bocs et al. 2003), a total of 5279 CDSs were predicted and submitted to automatic functional annotation (Vallenet et al. 2006). Each predicted gene was assigned a unique identifier prefixed with "FRAAL." Sequence data for comparative analyses were obtained from the NCBI databank (RefSeq section). Putative orthologs and synteny groups (conservation of the chromosomal co-localization between pairs of orthologous genes from different genomes) were computed between ACN and the 265 other complete genomes using the procedure described in Vallenet et al. (2006). Manual validation of the automatic annotation was performed using the MaGe (Magnifying Genomes) interface, which allows graphic visualization of the ACN annotations enhanced by a synchronized representation of synteny groups in other genomes chosen for comparisons. The ACN nucleotide sequence and annotation data have been deposited at EMBL databank under accession number CT573213. In addition, all the data (i.e., syntactic and functional annotations, and results of comparative analysis) were stored in a relational database, called FrankiaScope (Vallenet et al. 2006). This database is publicly available via the MaGe interface at http://www.genoscope.cns.fr/agc/mage/frankia/Login/log.php.

\section{Methods used for determining deleted, duplicated, strain-specific, and ORFan genes}

Genes deleted from one strain were identified by using reciprocal BLAST hits from each pair of genomes. That is, each pair of orthologs identified each other as the lowest BLAST score. Genes were scored as deleted if they did not have a reciprocal hit in another Frankia genome. The data set included three Frankia strains.

Gene duplications were assessed as having the best BLAST hits within the same genome (duplicates) using an E-value cut-off of $10^{-4}$ and a data set consisting of NR (minus Frankia sequences) + Kineococcus radiodurans + Streptomyces coelicolor + S. avermitilis + $\mathrm{ACN}+\mathrm{CcI} 3+\mathrm{EAN}$. To cluster duplicates, the program BlastClust (NCBI) was used with settings reported in the text.

Strain-specific genes (SSGs) include genes found in one but not another Frankia strain at an E-value cutoff of $10^{-4}$, plus genes that have no hits in databases. The latter are referrred to as ORFans.

\section{Acknowledgments}

This work was supported by the National Science Foundation Microbial Genome sequencing program to D.R.B., L.S.T., and M.P.F. The work on CcI3 and EAN was performed under the auspices of the U.S. Department of Energy's Office of Science, Biological, and Environmental Research Program, and by the University of California, Lawrence Livermore National Laboratory, and Los Alamos National Laboratory. The work on ACN14a was performed at Genoscope, Evry, France and was supported by CNRS/ACI Microbiologie and MRT/ACI IMPBio2004. Funds to Anita Sellstedt are from FORMAS and NFR, Sweden. Funds for the construction of the ACN BAC library were provided in part by the Genome Science and Technology Program, The University of Tennessee. Correspondence and requests for materials should be addressed to D.R.B. (david.benson@uconn.edu) for CcI3, to P.N. (normand@biomserv.univ-lyon1.fr) for ACN, and to L.S.T. (lst@hypatia.unh.edu) for EAN.

\section{References}

The Angiosperm Phylogeny Group (APG). 1998. An ordinal classification for the families of flowering plants. Ann. Mo. Bot. Gard. 85: $531-553$.

Bartolome, B., Jubete, Y., Martinez, E., and de la Cruz, F. 1991. Construction and properties of a family of pACYC184-derived cloning vectors compatible with pBR322 and its derivatives. Gene 102: $75-78$.

Batut, J., Andersson, S.G., and O'Callaghan, D. 2004. The evolution of chronic infection strategies in the $\alpha$-proteobacteria. Nat. Rev. Microbiol. 2: 933-945.

Benson, D.R., Vanden Heuvel, B.D., and Potter, D. 2004. Actinorhizal symbioses: Diversity and biogeography. In Plant microbiology (ed. M. Gillings). BIOS Scientific Publishers Ltd., Oxford.

Bentley, S.D., Chater, K.F., Cerdeno-Tarraga, A.M., Challis, G.L., Thomson, N.R., James, K.D., Harris, D.E., Quail, M.A., Kieser, H., Harper, D., et al. 2002. Complete genome sequence of the model actinomycete Streptomyces coelicolor A3(2). Nature 417: 141-147.

Berg, R.H. and McDowell, L. 1988. Cytochemistry of the wall of infected Casuarina actinorhizae. Can. J. Bot. 66: 2038-2047.

Bocs, S., Cruveiller, S., Vallenet, D., Nuel, G., and Medigue, C. 2003. AMIGene: Annotation of MIcrobial Genes. Nucleic Acids Res. 31: $3723-3726$.

Campbell, J.D. and Holden, A.M. 1984. Miocene casuarinacean fossils from Southland and Central Otago, New Zealand. N.Z. J. Bot. 22: $159-167$.

Chain, P., Kurtz, S., Ohlebusch, E., and Slezak, T. 2003. An applications-focused review of comparative genomics tools: Capabilities, limitations and future challenges. Brief. Bioinform. 4: $105-123$.

Chen, L.-M., Cui, Y., Qin, M., Wang, Y., Bai, X., and Ma, Q. 1991. Identification of a nodD-like gene in Frankia by direct complementation of a Rhizobium nodD-mutant. Mol. Gen. Genet. 233: 311-314.

Chen, W.M., Laevens, S., Lee, T.M., Coenye, T., De Vos, P., Mergeay, M. and Vandamme, P. 2001. Ralstonia taiwanensis sp. nov., isolated from root nodules of Mimosa species and sputum of a cystic fibrosis patient. Int. J. Syst. Evol. Microbiol. 51: 1729-1735.

Clawson, M.L., Bourret, A., and Benson, D.R. 2004. Assessing the phylogeny of Frankia-actinorhizal plant nitrogen-fixing root nodule symbioses with Frankia 16S rRNA and glutamine synthetase gene sequences. Mol. Phylogenet. Evol. 31: 131-138.

\section{Genome Research}

www.genome.org 
Crane, P.R. 1989. Early fossil history and evolution of the Betulaceae. In Evolution, systematics, and fossil history of the Hamamelidae (eds. P.R. Crane and S. Blackmore), pp. 87-116. Clarendon Press, Oxford.

Dufresne, A., Garczarek, L., and Partensky, F. 2005. Accelerated evolution associated with genome reduction in a free-living prokaryote. Genome Biol. 6: R14.

Ewing, B. and Green, P. 1998. Base-calling of automated sequencer traces using phred. II. Error probabilities. Genome Res. 8: 186-194.

Ewing, B., Hillier, L., Wendl, M.C., and Green, P. 1998. Base-calling of automated sequencer traces using phred. I. Accuracy assessment. Genome Res. 8: 175-185.

Francino, M.P. 2005. An adaptive radiation model for the origin of new gene functions. Nat. Genet. 37: 573-577.

Frost, L.S., Leplae, R., Summers, A.O., and Toussaint, A. 2005. Mobile genetic elements: The agents of open source evolution. Nat. Rev. Microbiol. 3: 722-732.

Gevers, D., Cohan, F.M., Lawrence, J.G., Spratt, B.G., Coenye, T., Feil, E.J., Stackebrandt, E., Van de Peer, Y., Vandamme, P., Thompson, F.L., et al. 2005. Opinion: Re-evaluating prokaryotic species. Nat. Rev. Microbiol. 3: 733-739.

Gordon, D., Abajian, C., and Green, P. 1998. Consed: A graphical tool for sequence finishing. Genome Res. 8: 195-202.

Ikeda, H., Ishikawa, J., Hanamoto, A., Shinose, M., Kikuchi, H., Shiba, T., Sakaki, Y., Hattori, M., and Omura, S. 2003. Complete genome sequence and comparative analysis of the industrial microorganism Streptomyces avermitilis. Nat. Biotechnol. 21: 526-531.

Kimura, M. 1980. A simple method for estimating evolutionary rates of base substitutions through comparative studies of nucleotide sequences. J. Mol. Evol. 16: 111-120.

Konstantinidis, K.T. and Tiedje, J.M. 2005. Genomic insights that advance the species definition for prokaryotes. Proc. Natl. Acad. Sci. 102: 2567-2572.

Lalonde, M., Calvert, H.E., and Pine, S. 1981. Isolation and use of Frankia strains in actinorhizae formation. In Current perspectives in nitrogen fixation (eds. A.H. Gibson and W.E. Newton), pp. 296-299. Australian Academy of Sciences, Canberra.

Luo, M. and Wing, R.A. 2003. An improved method for plant BAC library construction. Methods Mol. Biol. 236: 3-20.

Magallon, S., Crane, P.R., and Herendeen, P.S. 1999. Phylogenetic pattern, diversity, and diversification of eudicots. Ann. Mo. Bot. Gard. 86: $297-372$.

Markowitz, V., Korzeniewski, F., Palaniappan, K., Szeto, E., Werner, G. Padki, A., Zhao, X., Dubchak, I., Hugenholtz, P., Anderson, I., et al. 2006. The Integrated Microbial Genomes (IMG) system. Nucleic Acids Res. 34: D344-D348.

Mira, A., Ochman, H., and Moran, N.A. 2001. Deletional bias and the evolution of bacterial genomes. Trends Genet. 17: 589-596.

Moran, N.A. 2003. Tracing the evolution of gene loss in obligate bacterial symbionts. Curr. Opin. Microbiol. 6: 512-518.

Moulin, L., Munive, A., Dreyfus, B., and Boivin-Masson, C. 2001. Nodulation of legumes by members of the $\beta$-subclass of Proteobacteria. Nature 411: 948-950.

Moulin, L., Bena, G., Boivin-Masson, C., and Stepkowski, T. 2004. Phylogenetic analyses of symbiotic nodulation genes support vertical and lateral gene co-transfer within the Bradyrhizobium genus. Mol. Phylogenet. Evol. 30: 720-732.

Normand, P. and Fernandez, M.P. 2007. Evolution and diversity of Frankia. In Actinorhizal symbioses (ed. K. Pawlowski). Springer Verlag, London (in press).

Normand, P. and Lalonde, M. 1982. Evaluation of Frankia strains isolated from provenances of two Alnus species. Can. J. Microbiol. 28: 1133-1142.

Normand, P., Orso, S., Cournoyer, B., Jeannin, P., Chapelon, C. Dawson, J., Evtushenko, L., and Misra, A.K. 1996. Molecular phylogeny of the genus Frankia and related genera and emendation of family Frankiaceae. Int. J. Syst. Bacteriol. 46: 1-9.

Ochman, H. and Moran, N.A. 2001. Genes lost and genes found: Evolution of bacterial pathogenesis and symbiosis. Science 292: 1096-1099.

Ochman, H., Elwyn, S., and Moran, N.A. 1999. Calibrating bacterial evolution. Proc. Natl. Acad. Sci. 96: 12638-12643.

Saitou, N. and Nei, M. 1987. The neighbor-joining method: A new method for reconstructing phylogenetic trees. Mol. Biol. Evol. 4: $406-425$.

Sellstedt, A. 1995. Specificity and effectivity in nodulation by Frankia on southern hemisphere actinorhiza. FEMS Microbiol. Lett. 125: $231-236$.

Silvester, W.B. 1976. Ecological and economic significance of the non-legume symbiosis. In Proceedings of the First International Symposium on Nitrogen Fixation (eds. W.E. Newton and C.J. Nyman), pp. 489-506. Washington University Press, Pullman, Washington, D.C.

Silvester, W.B. 1977. Dinitrogen fixation by plant associations excluding legumes. In A Treatise on dinitrogen fixation (eds. R.W.F. Hardy and A.H. Gibson), pp. 141-190. John Wiley and Sons, New York.

Simonet, P., Navarro, E., Rouvier, C., Reddell, P., Zimpfer, J., Dommergues, Y., Bardin, R., Combarro, P., Hamelin, J., Domenach, A.-M., et al. 1999. Co-evolution between Frankia populations and host plants in the family Casuarinaceae and consequent patterns of global dispersal. Environ. Microbiol. 1: 525-533.

Soltis, D.E., Soltis, P.S., Morgan, D.R., Swensen, S.M., Mullin, B.C., Dowd, J.M., and Martin, P.G. 1995. Chloroplast gene sequence data suggest a single origin of the predisposition for symbiotic nitrogen fixation in angiosperms. Proc. Natl. Acad. Sci. 92: 2647-2651.

Swensen, S.M. 1996. The evolution of actinorhizal symbioses: Evidence for multiple origins of the symbiotic association. Am. J. Bot. 83: $1503-1512$.

Thompson, J.D., Gibson, T.J., Plewniak, F., Jeanmougin, F., and Higgins, D.G. 1997. The CLUSTAL_X windows interface: Flexible strategies for multiple sequence alignment aided by quality analysis tools. Nucleic Acids Res. 25: 4876-4882.

Vallenet, D., Labarre, L., Rouy, Z., Barbe, V., Bocs, S., Cruveiller, S., Lajus, A., Pascal, G., Scarpelli, C., and Médigue, C. 2006. MaGe-A microbial genome annotation system supported by synteny results. Nucleic Acids Res. 34: 53-65.

Vanden Heuvel, B.D., Benson, D.R., Bortiri, E., and Potter, D. 2004. Low genetic diversity among Frankia spp. strains nodulating sympatric populations of actinorhizal species of Rosaceae, Ceanothus (Rhamnaceae) and Datisca glomerata (Datiscaceae) west of the Sierra Nevada (California). Can. J. Microbiol. 50: 989-1000.

Wayne, L.G., Brenner, D.J., Colwell, R.R., Grimont, P.A.D., Kandler, O. Krichevsky, M.I., Moore, L.H., Moore, W.E.C., Murray, R.G.E. Stackebrandt, E., et al. 1987. Report of the ad hoc committee on reconciliation of approaches to bacterial systematics. Int. J. Syst. Bacteriol. 37: 463-464.

Young, J.P. and Haukka, K.E. 1996. Diversity and phylogeny of rhizobia. New Phytol. 133: 87-94.

Zhang, Z., Lopez, M.F., and Torrey, J.G. 1984. A comparison of cultura characteristics and infectivity of Frankia isolates from root nodules of Casuarina species. Plant Soil 78: 79-90.

Zimpfer, J.F., Smyth, C.A., and Dawson, J.O. 1997. The capacity of Jamaican mine spoils, agricultural and forest soils to nodulate Myrica cerifera, Leucaena leucocephala and Casuarina cunninghamiana. Physiol. Plant. 99: 664-672.

Received August 1, 2006; accepted in revised form October 18, 2006. 


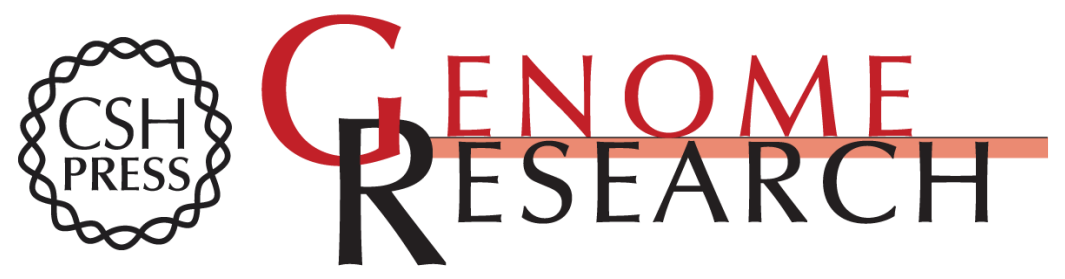

\section{Genome characteristics of facultatively symbiotic Frankia sp. strains reflect host range and host plant biogeography}

Philippe Normand, Pascal Lapierre, Louis S. Tisa, et al.

Genome Res. 2007 17: 7-15 originally published online December 6, 2006 Access the most recent version at doi:10.1101/gr.5798407

References This article cites 44 articles, 6 of which can be accessed free at: http://genome.cshlp.org/content/17/1/7.full.html\#ref-list-1

\section{License}

Email Alerting Receive free email alerts when new articles cite this article - sign up in the box at the Service top right corner of the article or click here.

\section{Affordable, Accurate Sequencing.}

